\title{
Implementation of robotics in total joint arthroplasty
}

This article was published in the following Dove Press journal:

Robotic Surgery: Research and Reviews

9 September 2015

Number of times this article has been viewed

\author{
Alexander $\mathrm{H}$ Jinnah' \\ Ashley Multani ${ }^{2}$ \\ Johannes F Plate' \\ Gary G Poehling' \\ Riyaz H Jinnah ${ }^{1,3}$
}

'Department of Orthopaedic Surgery, Wake Forest School of Medicine, Winston-Salem, NC, USA; ${ }^{2}$ Windsor University School of Medicine, St Kitts, West Indies; ${ }^{3}$ Southeastern Orthopedics, Southeastern Regional Medical Center, Lumberton, NC, USA
Correspondence: Riyaz H Jinnah Southeastern Orthopedics, Southeastern Regional Medical Center, 300 West 27th Street Lumberton, NC 28358, USA

Email rjinnah@wakehealth.edu
Abstract: Robotic-assisted systems for unicompartmental and total knee arthroplasty and total hip arthroplasty have been introduced in recent years. Various systems are currently in use ranging from passive to robotic-assisted and active systems to improve component alignment with the goal to improve longevity of knee and hip prostheses. The purpose of this article is to review contemporary robotic systems for knee and hip arthroplasty and provide an overview of current implant survivorships based on registry data. We conducted a PubMed search for robotic systems used in orthopedics with a particular focus on total joint arthroplasty, in order to review the success of the implementation of these systems. While some of the current systems are still in their infancy and costs may be considered prohibitive, robotic systems continue to evolve and have become an addition to the orthopedic surgeon's armamentarium.

Keywords: hip, knee, replacement, orthopedic surgery

\section{Introduction}

Evolution of surgery has been driven by the development of tools, and the latest apparatus to enter the operating room is robotic instrumentation. ${ }^{1}$ Robotics is defined as a field of engineering that deals with machines that manage a task by mimicking human behavior. ${ }^{2,3}$ Considering the favorable outcomes in other fields of work, there has been significant impetus to implement robotics in medicine. ${ }^{4}$ Since robotics was first introduced in medicine in 1985, they have been proven to be advantageous, particularly in the surgical coliseum. ${ }^{5}$ They have augmented technical improvements in surgical procedures, which were hitherto impossible because of the inconsistency of the human hand. ${ }^{4}$ Some subspecialties, such as urology, gastroenterology, oncology, and gynecology, have embraced this change more than others have. ${ }^{3,6-11}$ However, one of the first robots in surgery was the PUMA 200 - developed to help neurosurgeons perform stereotactic brain biopsy with $0.05 \mathrm{~mm}$ accuracy. ${ }^{12}$ Orthopedic surgery forayed into the use of robotics in the mid 1980s, pioneered by William Barger and Hap Paul with the development and introduction of ROBODOC (Curexo Technology Corporation, originally by Integrated Surgical Systems). ${ }^{13}$ Three-dimensional (3D) imaging relayed to the robot enabled more accurate placement of the prosthesis. However, the usage of this system was limited due to technical complications directly related to the robotic device. ${ }^{14}$

In the early 2000 s, robotic systems that were passive and haptic began to emerge in the orthopedic community. ${ }^{15}$ The two primary systems that were first available included the active constraint robot and the RIO robotic arm (MAKO Surgical Corp, Fort Lauderdale, FL, USA), which were used for unicompartmental knee 
arthroplasties (UKAs). In 2006, Professor Justin Cobb et al released the first clinical series of the active constraint robot in the UK with promising results. ${ }^{16}$ Following this, the RIO robotic arm received US Food and Drug Administration approval in the US in 2008. Robotics has provided greater precision in bone resection and subsequent soft tissue balancing for UKA. ${ }^{17}$ UKA for end-stage degenerative disease of the knee limited to one compartment is a procedure that has shown vast improvement in short-term results with the use of robotics. ${ }^{18}$ These robot-assisted systems with haptic guidance for bone resection during UKA are the focal operative technique in this paper. Robotic-assisted systems have been shown to provide accurate positioning and alignment with real-time ligament balancing. ${ }^{18}$ During UKA, bone resection can be more accurately performed by haptic guidance provided to the surgeons by the roboticassisted systems. ${ }^{19}$ The same RIO hardware used for UKA is recently being employed with MAKO hip software for total hip arthroplasty (THA) as a new haptic feedback system. The system provides increased accuracy of the acetabular cup implant placement. ${ }^{20}$ The improved alignment and contact between the implant and bone avoids impingement and may improve functional outcome and longevity of the implant. $^{21}$

\section{Current orthopedic robotic systems}

The main objective of this paper is to present the past and current robotic systems available in orthopedic surgery with a primary focus on the current and evolving technologies available for total joint arthroplasty. In this paper, we review studies evaluating the implementation of robotic systems into the orthopedic operating room.

\section{Materials and methods}

Robotics has been in the orthopedic operating room since 1985. We first reviewed all published articles using PubMed and searching using the search terms "Robotics" AND "Surgery" in order to establish the history of robotic systems used in the surgical setting. We then only included articles in English. Following this, we narrowed the search to include "Orthopedics" to allow us to develop a timeline for the implementation of robots into this specific area of surgery. Finally, we narrowed our search by adding either total knee arthroplasty (TKA), THA, or UKA to the search criteria in order to investigate the specific history in relation to the systems of greatest interest to the authors. We then reviewed the data specific to each of these procedures and analyzed it accordingly, with a primary focus on human studies comparing the robotic systems to the corresponding conventional manual technique. No statistical analysis was performed in this review.

\section{Active robotic systems}

Active robotic systems are systems that complete the operation without surgical assistance. The manner in which this is achieved is by using preoperative computed tomography (CT) scans and formulating an operative plan, which is input into a corresponding surgical software that instructs the robot exactly what to do and when. ${ }^{22}$ The procedure is monitored by the surgeon and can be stopped at any time for safety purposes.

The first active robotic system in orthopedics was the ROBODOC (Curexo Technology Corporation) in 1992. ${ }^{23,24}$ The ROBODOC was initially designed in order to decrease the incidence of an inappropriately prepared implant cavity during a THA. ${ }^{25}$ This system consisted of a preoperative planning workstation (ORTHODOC) and the ROBODOC surgical system. The preoperative planning using ORTHODOC created a 3D image using CT scans and allowed for appropriate surgical scenarios to be foreseen. The ROBODOC has since seen an expansion in its applications to include assisting with TKAs as well. However, some feel that it has fallen out of favor within the orthopedic community due to conflicting data seen in regard to clinical outcomes and the large initial investment required. ${ }^{26,27}$ However, recently there has been a resurgence of interest and they are developing new software and hardware to fulfill the need of surgeons.

In 1997, another active system was introduced, the computer-assisted surgical planning and robotics (CASPAR) system. ${ }^{5}$ The CASPAR system automatically performed bone drilling from a preoperative plan based on CT data. This system is no longer available; however, it was considered to be a direct competitor to ROBODOC due to its similar function.

\section{Haptic robotic systems}

Haptic systems are also known as synergistic systems that combine the skills of the surgeon with the capabilities of the robot to give the surgeon control of the operation. ${ }^{24}$ Like the active systems, the haptic systems use preoperative CT scans to create a 3D model of the patients' native anatomy. This allows the surgeon to plan the surgical procedure, including which components to use and what sizes are required. Intraoperatively, certain predetermined reference points are identified that allow the software to orient the robot to the 
anatomy of patients and compare it to the $3 \mathrm{D}$ representation created preoperatively. The difference between the haptic system and the active system is that the surgeon has complete control of the robot during the procedure, and the robot only intervenes by making suggestions and assisting in creating exact cutting zones.

There are currently two haptic robotic systems available for use in orthopedics. The first of these is the RIO robotic arm. The RIO was released in 2008 and is used to assist with the implantation of UKAs. The RIO arm is designed to allow the surgeon to execute the preoperative plan, whilst restricting the surgeons cutting zone by resisting any movement outside of the planned cutting area during the milling procedure. $^{5,24}$

The other haptic device that is currently available in orthopedics is the Navio PFS (Blue Belt Technologies, CE Mark 2012). The Navio PFS is similar to the RIO system in its use; however, the Navio PFS robot does not require a preoperative CT scan. Instead, this system uses intraoperative planning by tracking the drill tool during the procedure and having the drill bit retract when it leaves the planned cutting volume. However, there is limited information currently available in regard to this newly developed system. ${ }^{5,28}$ The other haptic system that has been developed but is no longer available is the Stanmore Sculptor (Stanmore Implants Worldwide Ltd), which was a direct competitor of the RIO system due to similarities between them.

\section{Passive robotic systems}

Passive robotic systems are also known as navigation systems. These navigation systems assist the surgeon with preoperative planning, simulation, and intraoperative guidance. The main difference between these systems and the aforementioned active and haptic systems is that there is no direct action taken by these systems. ${ }^{5}$ Furthermore, the main purpose of these systems is to help create $3 \mathrm{D}$ visualization of the patient's anatomy to assist with the preoperative planning and provide detailed information intraoperatively, such as feedback on joint biomechanics to make recommendations, as well as provide information on the accuracy of the bone cuts that have been made. ${ }^{22,24}$

\section{Discussion \\ Robotic unicompartmental knee arthroplasty}

The abovementioned are the robotic systems that are currently increasingly used in the orthopedic community, although as of yet they are not the standard of care. To date, there are 250 RIO robotic arms in use that have assisted with over 50,000 UKAs and 8,300 THAs in the US since its inception in 2007. Whether or not this will lead to better outcomes will only become evident with time. However, short-term results published by Conditt et al have shown a promising 2-year failure rate of only $1.1 \%$ in 701 robot-assisted UKAs. ${ }^{29}$ Similarly, Plate et al reviewed the outcomes of 746 robotic-assisted UKA and the influence of body mass index on revision rate. ${ }^{30}$ The overall revision rate to TKA was $5.8 \%$ at a mean follow-up of 34.6 months, which was comparable to the outcomes of conventional UKA in selected national registries (Table 1). ${ }^{30-33}$ These survivorship figures compare favorably to those found by Conditt et $\mathrm{al}^{29}$ and Goddard et $\mathrm{al}^{34}$ when using robotic assistance while performing UKAs.

The other major supposed advantage of the RIO system is soft tissue balancing. Whiteside showed us that the success of knee surgery heavily relies on proper soft tissue balancing. ${ }^{35}$ Furthermore, Plate et al demonstrated with 52 consecutive medial UKAs that real-time dynamic ligament balancing using robotic assistance reproduced the preoperative planned ligamentous balance with a variation of $<1 \mathrm{~mm}$ in $83 \%$ of their cases, and thus concluded that high level of accuracy and repeatability can be achieved using robotic assistance. ${ }^{18}$ Utilizing virtual surgery allows the surgeon to fine-tune the prosthesis and bone resection to allow for change in soft tissue balancing. Multiple authors have also suggested that roboticassisted UKA leads to improved component positioning. ${ }^{19,36}$ Lonner et al compared the radiographic outcomes of 31 consecutive robotic UKAs and 27 manual UKAs. ${ }^{19}$ The results showed that the average error in the coronal plane when

Table I Outcomes of UKA in national registries compared to robotic-assisted UKA

\begin{tabular}{lllll}
\hline Registry & Years analyzed & Number of UKAs & 3-year revision rate (\%) & Revision rate at longest follow-up \\
\hline Australia & $1999-2012$ & 36,971 & 6.0 & $16.3 \%(\mathrm{II}$ yrs $)$ \\
New Zealand & $2000-201 \mathrm{I}$ & 6,621 & 4.7 & $12.1 \%(\mathrm{IO} \mathrm{yrs})$ \\
Norway & $2000-2010$ & 3,928 & $\sim 6.5$ & $9.6 \%(10 \mathrm{yrs})$ \\
Sweden & $200 \mathrm{I}-2010$ & 3,195 & $\sim 6$ & $12.5 \%(10 \mathrm{yrs})$ \\
UK & $2003-201 \mathrm{I}$ & 11,125 & 4.72 & $10.82 \%(8 \mathrm{yrs})$ \\
Plate et al & $2008-201 \mathrm{I}$ & 746 & 5.8 & \\
\hline
\end{tabular}

Note: Adapted from Springer and the Knee Surgery, Sports Traumatology, Arthroscopy, 20I5:doi: 10.1007/s00 I67-0I5-3597-5, Plate JF, Augart MA, Seyler TM, et al, Table 6. With kind permission from Springer Science and Business Media. ${ }^{30}$

Abbreviations: UKA, unicompartmental knee arthroplasty; yrs, years. 
using manual instruments was $2.7^{\circ} \pm 2.1^{\circ}$ more varus for the tibial component, relative to the mechanical axis of the tibia compared to $0.2^{\circ} \pm 0.8^{\circ}$ with robotic assistance. Furthermore, the varus/valgus root mean square error was $3.4^{\circ}$ manually and $1.8^{\circ}$ with robotic assistance. Malposition of components by as little as $2^{\circ}$ during UKA has been shown to lead to failure because normal joint biomechanics are altered without achieving proper ligamentous balance, possibly leading to increased polyethylene wear and accelerated progression of degenerative disease of the uninvolved compartment. ${ }^{18,19,37-43}$ We think that these aspects are particularly important for functional outcomes of UKA and will enable longer term survival of prosthesis.

There has been some concern that the introduction of robotic hardware into the operating room may affect its sterility. However, despite the fact that robotics have been used relatively common since the early 2000 s, there has been no increase in wound problems or infection rates. Kuper and Rosenstein ${ }^{44}$ reported in 2008 the incidence of infection following primary total joint arthroplasty to be between $0.3 \%$ and $2 \%$, and a more recent study by Mcann ${ }^{45}$ quotes the infection rate for total hip and knee replacements to be between $0.67 \%$ and $2.4 \%$. Therefore, it appears that these concerns are probably unfounded. There is no doubt that introduction of a robot into the operating room creates bulky equipment into the operating milieu, but with the developments and advances taking place in this evolving technology era, they will continue to miniaturize the hardware and this would negate this concern. As a matter of fact, there are already companies working on the development of handheld robotic systems without the need for the bulky parent robot. Additionally, some have suggested that the improvements seen with robotic assistance are minimal and hence not worth the large economic investment. ${ }^{46}$ These arguments are valid; however, we believe that with the increasing use of these systems, surgeons will become more comfortable with them leading to greater improvements in radiographic and clinical outcomes. Furthermore, Pearle et al believe that the learning curve for the use of these robots may be shorter, especially for surgeons in the early stages of their training. ${ }^{47}$

\section{Robotic THA}

We have found that the largest limitation to THA is the improper implantation of the acetabular cup. ${ }^{20}$ This can lead to several complications, including dislocation, impingement, leg length discrepancy, accelerated wear, and revision surgery. ${ }^{4-53}$ Dorr et al suggested that the main reason why acetabular cup malposition is common is due to the assumption and application of normality to the THA. ${ }^{54}$ Several authors have proven that hip anatomy is individual, and hence, applying general rules to each individual patient can result in improper cup positioning, leading to all the above-stated complications. ${ }^{55-59}$

Robotics was thought to be the ideal way of solving this problem. THA was one of the first orthopedic procedures that used robotics with the introduction of ROBODOC in 1992. ${ }^{15,25}$ This was an active system that fell out of favor with surgeons due to their limited involvement in the surgery as well as results showing higher dislocation and revision rates than conventional methods. ${ }^{25,60}$ After this, there was a long period where only THAs were performed. More recently, there has been the introduction of a haptic feedback system by $\mathrm{MAKO}^{\mathrm{TM}}$ using the same $\mathrm{RIO}^{\circledR}$ hardware that is used for their UKAs, but utilizing MAKO ${ }^{\mathrm{TM}}$ robotic hip system software.

Dorr et al believe that the $\mathrm{RIO}^{\circledR}$ system will eliminate the improper implantation of the acetabular cup by providing the exact center of rotation of the acetabulum with preoperative planning and intraoperative robotic navigation. ${ }^{54}$ This information will allow the correct femur bony neck cut to reconstruct the desired leg length and offset.

Leg length discrepancy is currently one of the most common orthopedic complications associated with medical litigation, and is associated with adverse short- and longterm outcomes if $>1 \mathrm{~cm} .{ }^{61,62} \mathrm{El}$ Bitar et al retrospectively analyzed 61 robotic-assisted THAs radiographically to assess for leg length discrepancy. ${ }^{63}$ In this study, the authors found the mean radiographic postoperative leg length discrepancy to be $2.5 \mathrm{~mm}$, with $89.8 \%$ of measurements at $5 \mathrm{~mm}$ or less and $100 \%$ at $100 \mathrm{~mm}$ or less. Owing to these results, the authors concluded that the use of robotic assistance allowed for accurate and reproducible THA while minimizing the leg length discrepancy.

Domb et al performed a matched-pair control study to compare in a 1:1 ratio manual THA (50) and robotic THA (50) performed by a single surgeon. ${ }^{20}$ The authors analyzed the acetabular cup placement using TraumaCad ${ }^{\mathrm{TM}}$ software (build number 2.2.5350.0, 2012; Voyant Health ${ }^{\circledR}$, Petach-Tikva, Israel) to calculate the number of hips in the safe zones of Lewinnek et $\mathrm{al}^{50}$ (inclination, $30^{\circ}-50^{\circ}$; anteversion, $5^{\circ}-25^{\circ}$ ) and Callanan et $\mathrm{l}^{52}$ (inclination, $30^{\circ}-45^{\circ}$; anteversion, $5^{\circ}-25^{\circ}$ ). The results of this study showed that $100 \%(50 / 50)$ of the robotically placed acetabular cups were in the safe zone of Lewinnek et al, ${ }^{50}$ compared to only $80 \%(40 / 50)$ in the manual THA group. Furthermore, $92 \%(46 / 50)$ of cups in the robotic THA group were in 
the safe zone of Callanan et al ${ }^{52}$ compared to $62 \%(31 / 50)$ of the acetabular cups in the conventional THA group. Given these outcomes, the authors concluded that using robotic assistance for THA will produce more accurate and reproducible radiographic outcomes and hence lead to less short- and long-term adverse effects.

Despite the promising early radiographic results seen using the haptic robotic guidance for THA, further studies must be done. There are currently no clinical studies to the author's knowledge evaluating the short- and long-term outcomes of robotically assisted THA; therefore, this is the obvious next step in order to begin to form a well-informed opinion on this system's ability to improve clinical outcomes and longevity.

\section{Limitations of robotics in surgery}

Despite the promising results seen using robotics in the operating room, there are several limitations that must be taken into account. The first of these includes the increased operative setup time because of the need to prepare the robot and all of the associated accessories. One study (Hansen et $\mathrm{al}^{46}$ ) found that the use of robotic UKA versus manual UKA increased operative time by an average of 20 minutes. According to Hansen et al, ${ }^{46}$ this could represent an increased cost of US $\$ 2,466-\$ 9,220$. However, our experience using the robotic system has actually found the use of the robot to improve operative efficiency and decrease the average operative time. We believe this is due to the surgical team's familiarity with the robot at our institution, and hence, the authors suggest that a rule to go by when the robotic system is first introduced is to always assure a clear unobstructed path be left between the robot and infrared markers during critical points of the procedure.

Robotic-assisted orthopedic surgery is currently only available at selected institutions. The implementation of this technology may warrant a structured training program for residency who may utilize robotic-assisted surgery in the future. It is the authors' belief that the startup cost of a robotic system is justified with our experience; however, for smaller low volume surgical centers, the startup cost may be prohibitive. We believe that more consistent and long-term data favoring the use of robotic systems are required before the cost can be uniformly justified.

\section{Limitations to review}

The main limitation of this review is that the research that has been evaluated involves short- to medium-term data, with no long-term results. However, this is an unavoidable consequence to researching the newer innovations in the orthopedic community. Hence, the authors recommend that further studies with long-term results be completed when the data are available. A further limitation in this review is the sole use of PubMed as our database; therefore, it is possible that we excluded relevant studies. Although, we feel that the pertinent subject matter was analyzed.

\section{Conclusion}

Robotics has been a welcomed and inevitable addition to our armamentarium into the surgical milieu. As with all innovations, the cost is of concern, but with wider acceptance and use, these concerns should certainly dissipate. Since so much of surgery is dependent on accuracy and repetition, we think it is inevitable that robotics will become a familiar asset in the operating room. The true value of robotics, however, will only be realized if we can show improved outcomes in the long term. We must continue to critically analyze our results to reach a definitive conclusion.

\section{Disclosure}

AJ, AM, and JFP report no conflicts of interest. GGP and RHJ have received financial support and are consultants of MAKO Surgical Corp. All authors certify that this investigation was performed in conformity with ethical principles of research.

\section{References}

1. Parekattil SJ, Moran ME. Robotic instrumentation: evolution and microsurgical applications. Indian J Urol. 2010;26(3):395-403.

2. Simpson J, Weiner, E. Oxford English Dictionary. 3rd ed. Oxford, UK: Oxford University Press; 2013.

3. Satava RM. Surgical robotics: the early chronicles: a personal historical perspective. Surg Laparosc Endosc Percutan Tech . 2002;12(1):6-16.

4. Hussain A, Malik A, Halim MU, Ali AM. The use of robotics in surgery: a review. Int J Clin Pract. 2014;68(11):1376-1382.

5. Beasley R. Medical robots: current systems and research directions. J Robot. 2012;2012:14.

6. Davies B. A review of robotics in surgery. Proc Inst Mech Eng H. 2000;214:129-140.

7. Alibhai MH, Shah SK, Walker PA, Wilson EB. A review of the role of robotics in bariatric surgery. J Surg Oncol. Epub 2015 May 7.

8. Sgarbura O, Tomulescu V, Popescu I. Robotic oncologic complexity score - a new tool for predicting complications in computer-enhanced oncologic surgery. The International Journal of Medical Robotics and Computer Assisted Surgery. Epub 2015 May 5.

9. Coker AM, Barajas-Gamboa JS, Cheverie J, et al. Outcomes of robotic-assisted transhiatal esophagectomy for esophageal cancer after neoadjuvant chemoradiation. J Laparoendosc Adv Surg Tech A. 2014; 4(2):89-94.

10. Lörincz B, Busch C, Möckelmann N, Knecht R. Initial learning curve of single-incision transaxillary robotic hemi- and total thyroidectomy a single team experience from Europe. Int J Surg. 2015;18: 118-122.

11. Guerra F, Pesi B, Amore Bonapasta S, et al. Challenges in robotic distal pancreatectomy: systematic review of current practice. Minerva Chir. 2015;70(4):241-247. 
12. Available from: http://www.biomed.brown.edu/Courses/BI108/ BI108_2005_Groups/04/neurology.html. Accessed January 4, 2015.

13. Lanfranco AR, Castellanos AE, Desai JP, Meyers WC. Robotic surgery: a current perspective. Ann Surg. 2004;239(1):14-21.

14. Schulz AP, Seide K, Queitsch C, et al. Results of total hip replacement using the ROBODOC surgical assistant system: clinical outcome and evaluation of complications for 97 procedures. Int J Med Robot. 2007; 3(4):301-306.

15. Hockstein NG, Gourin CG, Faust RA, Terris DJ. A history of robots: from science fiction to surgical robots. J Robot Surg. 2007;1:113-118.

16. Cobb J, Henckel J, Gomes P, et al. Hands-on robotic unicompartmental knee replacement: a prospective, randomised controlled study of the acrobot system. J Bone Joint Surg Br. 2006;88(2):188-197.

17. Najarian S, Fallahnezhad M, Afshari E. Advances in medical robotic systems with specific applications in surgery - a review. J Med Eng Technol. 2011;35:19-33.

18. Plate JF, Mofidi A, Mannava S, et al. Achieving accurate ligament balancing using robotic-assisted unicompartmental knee arthroplasty. Adv Orthop. 2013;2013:837167.

19. Lonner JH, John TK, Conditt MA. Robotic arm-assisted UKA improves tibial component alignment: a pilot study. Clin Orthop Relat Res. 2010;468:141-146.

20. Domb BG, El Bitar YF, Sadik AY, Stake CE, Botser IB. Comparison of robotic-assisted and conventional acetabular cup placement in THA: a matched-pair controlled study hip. Clin Orthop Relat Res. 2014;472: 329-336.

21. Tarwala R, Dorr LD. Robotic assisted total hip arthroplasty using the MAKO platform. Curr Rev Musculoskelet Med. 2011;4(3): 151-156.

22. Health Quality Ontario. Computer-assisted hip and knee arthroplasty. Navigation and active robotic systems: an evidence-based analysis. Ont Health Technol Assess Ser. 2004;4:1-39.

23. Davies BL, Rodriguez y Baena FM, Barrett AR, et al. Robotic control in knee joint replacement surgery. Proc Inst Mech Eng H. 2007;221: 71-80.

24. Lang JE, Mannava S, Floyd AJ, et al. Robotic systems in orthopaedic surgery. J Bone Joint Surg Br. 2011;93:1296-1299.

25. Sugano N. Computer-assisted orthopaedic surgery and robotic surgery in total hip arthroplasty. Clin Orthop Surg. 2013;5:1-9.

26. Liow MHL, Xia Z, Wong MK, Tay KJ, Yeo SJ, Chin PL. Robot-assisted total knee arthroplasty accurately restores the joint line and mechanical axis. A prospective randomised study. J Arthroplasty. 2014; 29(12):2373-2377.

27. Song EK, Seon JK, Yim JH, Netravali NA, Bargar WL. Robotic-assisted TKA reduces postoperative alignment outliers and improves gap balance compared to conventional TKA knee. Clin Orthop Relat Res. 2013;471:118-126.

28. Yen P-L, Davies BL. Active constraint control for image-guided robotic surgery. Proc Inst Mech Eng H. 2010;224:623-631.

29. Conditt M, Coon T, Roche M, et al. Two year survivorship of robotically guided unicompartmental knee arthroplasty. J Bone Joint Surg Br. 2013;95-B:294

30. Plate JF, Augart MA, Seyler TM, et al. Obesity has no effect on outcomes following unicompartmental knee arthroplasty. Knee Surg Sports Traumatol Arthrosc. 2015:doi: 10.1007/s00167-015-3597-5.

31. New Zealand Orthopaedic Association. The New Zealand Joint Registry Fourteen Year Report. New Zealand: New Zealand Orthopaedic Association; 2014. Available from: http://www.nzoa.org.nz/system/ files/NZJR2014Report.pdf. Accessed March 1, 2015.

32. National Joint Registry. National Joint Registry 11th Annual Report 2014. Hemel Hempstead: National Joint Registry; 2014. Available from: http://www.njrcentre.org.uk/njrcentre/Portals/0/Documents/England/ Reports/11th_annual_report/NJR\%2011th\%20Annual\%20Report $\% 20$ 2014.pdf. Accessed August 12, 2015.

33. Graves S, Davidson D, Ingerson L, et al. The Australian orthopaedic association national joint replacement registry. Med J Aust. 2004;180 (5 Suppl):S31-34.
34. Goddard MS, Lang JE, Bircher JS, Lu B, Poehling GG, Jinnah RH. Outcomes of 500 consecutive robot-assisted unicompartmental knee arthroplasty procedures. J Bone Joint Surg Br. 2012;94-B:75.

35. Whiteside LA. Making your next unicompartmental knee arthroplasty last: three keys to success. J Arthroplasty. 2005;20:2-3.

36. Roche M, O'Loughlin PF, Kendoff D, Musahl V, Pearle AD. Robotic armassisted unicompartmental knee arthroplasty: preoperative planning and surgical technique. Am J Orthop (Belle Mead NJ). 2009;38: 10-15.

37. Conditt MA, Roche MW. Minimally invasive robotic-arm-guided unicompartmental knee arthroplasty. J Bone Joint Surg Am. 2009; 91(Suppl 1):63-68.

38. Pearle AD, Kendoff D, Musahl V. Perspectives on computer-assisted orthopaedic surgery: movement toward quantitative orthopaedic surgery. J Bone Joint Surg Am. 2009;91(Suppl 1):7-12.

39. Banks SA, Harman MK, Hodge WA. Mechanism of anterior impingement damage in total knee arthroplasty. J Bone Joint Surg Am. 2002; 84-A (Suppl):37-42.

40. Mariani EM, Bourne MH, Jackson RT, Jackson ST, Jones P. Early failure of unicompartmental knee arthroplasty. J Arthroplasty. 2007;22: 81-84.

41. Collier MB, Eickmann TH, Sukezaki F, McAuley JP, Engh GA. Patient, implant, and alignment factors associated with revision of medial compartment unicondylar arthroplasty. J Arthroplasty. 2006;21:108-115.

42. Hernigou P, Deschamps G. Alignment influences wear in the knee after medial unicompartmental arthroplasty. Clin Orthop Relat Res. 2004;423:161-165.

43. Park SE, Lee CT. Comparison of robotic-assisted and conventional manual implantation of a primary total knee arthroplasty. J Arthroplasty. 2007;22:1054-1059.

44. Kuper M, Rosenstein A. Infection prevention in total knee and total hip arthroplasties. Am J Orthop (Belle Mead NJ). 2008;37:E2-E5.

45. Mcann PD. Preventing surgical site infection: preoperative bathing. Am J Orthop. 2013;42(6 Suppl):S5-S8.

46. Hansen D, Kusuma S, Palmer R, Harris K. Robotic guidance does not improve component position or short-term outcome in medial unicompartmental knee arthroplasty. J Arthroplasty. 2014;29(9): 1784-1789.

47. Pearle AD, O'Loughlin PF, Kendoff DO. Robot-assisted unicompartmental knee arthroplasty. J Arthroplasty. 2010;25:230-237.

48. Khan RJK, Carey Smith RL, Alakeson R, Fick DP, Wood D. Operative and non-operative treatment options for dislocation of the hip following total hip arthroplasty. Cochrane Database Syst Rev. 2006;4: CD005320.

49. Biedermann R, Tonin A, Krismer M, Rachbauer F, Eibl G, Stöckl B. Reducing the risk of dislocation after total hip arthroplasty: the effect of orientation of the acetabular component. J Bone Joint Surg Br. 2005;87: 762-769.

50. Lewinnek GE, Lewis JL, Tarr R, Compere CL, Zimmerman JR. Dislocations after total hip-replacement arthroplasties. $J$ Bone Joint Surg Am. 1978;60:217-220.

51. Kennedy JG, Rogers WB, Soffe KE, Sullivan RJ, Griffen DG, Sheehan LJ. Effect of acetabular component orientation on recurrent dislocation, pelvic osteolysis, polyethylene wear, and component migration. J Arthroplasty. 1998;13:530-534.

52. Callanan MC, Jarrett B, Bragdon CR, et al. The John Charnley Award: risk factors for cup malpositioning: quality improvement through a joint registry at a tertiary hospital. Clin Orthop Relat Res. 2011; 469(2):319-329.

53. Morrey BF. Difficult complications after hip joint replacement. Dislocation. Clin Orthop Relat Res. 1997;344:179-187.

54. Dorr LD, Jones RE, Padgett DE, Pagnano M, Ranawat AS, Trousdale RT. Robotic guidance in total hip arthroplasty: the shape of things to come. Orthopedics. 2011;34:e652-e655.

55. Harris WH. The correlation between minor or unrecognized developmental deformities and the development of osteoarthritis of the hip. Instr Course Lect. 2009;58:257-259. 
56. Lazennec JY, Boyer P, Gorin M, Catonné Y, Rousseau MA. Acetabular anteversion with CT in supine, simulated standing, and sitting positions in a THA patient population. Clin Orthop Relat Res. 2011;469: 1103-1109.

57. Dorr LD, Wan Z, Malik A, Zhu J, Dastane M, Deshmane P. A comparison of surgeon estimation and computed tomographic measurement of femoral component anteversion in cementless total hip arthroplasty. J Bone Joint Surg Am. 2009;91:2598-2604.

58. Zhu J, Wan Z, Dorr LD. Quantification of pelvic tilt in total hip arthroplasty. Clin Orthop Relat Res. 2010;468:571-575.

59. Little NJ, Busch CA, Gallagher JA, Rorabeck CH, Bourne RB. Acetabular polyethylene wear and acetabular inclination and femoral offset. Clin Orthop Relat Res. 2009;467:2895-2900.
60. Honl M, Dierk O, Gauck C, et al. Comparison of robotic-assisted and manual implantation of a primary total hip replacement. A prospective study. J Bone Joint Surg Am. 2003;85-A(8):1470-1478.

61. Hofmann AA, Skrzynski MC. Leg-length inequality and nerve palsy in total hip arthroplasty: a lawyer awaits! Orthopedics. 2000;23: 943-944.

62. Edwards BN, Tullos HS, Noble PC. Contributory factors and etiology of sciatic nerve palsy in total hip arthroplasty. Clin Orthop Relat Res. 1987;218:136-141.

63. El Bitar YF, Jackson TJ, Lindner D, Botser IB, Stake CE, Domb BG. Predictive value of robotic assisted total hip arthroplasty. Orthopedics. 2015;38(1):e31-e37.

\section{Publish your work in this journal}

Robotic Surgery: Research and Reviews is an international, peer reviewed, open access, online journal publishing original research, commentaries, reports, and reviews on the theory, use and application of robotics in surgical interventions. Articles on the use of supervisory-controlled robotic systems, telesurgical devices, and shared-control systems are invited. The manuscript management system is completely online and includes a very quick and fair peer review system, which is all easy to use. Visit http://www.dovepress.com/testimonials.php to read real quotes from published authors.

Submit your manuscript here: http://www.dovepress.com/robotic-surgery-research-and-reviews-journal 